\title{
Characterization of the inflammatory response to four commercial bone graft substitutes using a murine biocompatibility model
}

This article was published in the following Dove Press journal:

Journal of Inflammation Research

17 January 2012

Number of times this article has been viewed

\author{
David C Markel' \\ S Trent Guthrie ${ }^{2}$ \\ Bin $\mathrm{Wu}^{3}$ \\ Zheng Song ${ }^{4}$ \\ Paul H Wooley ${ }^{4}$ \\ 'Department of Orthopaedics, \\ Providence Hospital and Medical \\ Centers, Southfield, MI, ${ }^{2}$ Henry Ford \\ Hospital, Detroit, MI, ${ }^{3}$ Department of \\ Biomedical Engineering, Wayne State \\ University, Detroit, MI, ${ }^{4}$ Orthopaedic \\ Research Institute, Wichita, KS, USA
}

Correspondence: Paul H Wooley Orthopedic Research Institute, 929 North St Francis, Wichita, KS 67214, USA

Tel +I 3162685486

Fax + I $31629 \mid 4998$

Email paul.wooley@ncibor.org

\begin{abstract}
Bone grafting is utilized in nearly all orthopedic subspecialties and in most anatomic regions. Bone graft substitutes have the potential to offer similar efficacy as autogenous grafts without the morbidity of harvest. Several studies have noted the efficacy of new-generation bone substitute products, but few studies have evaluated their safety. This study characterizes and quantifies the inflammatory reaction to four different commercially available bone graft substitutes, which were examined using the in vivo murine air pouch biocompatibility model. One coralline hydroxyapatite product was chosen as an example of a purely osteoconductive material. Three demineralized bone matrix products were chosen to represent products that are both osteoconductive and osteoinductive. Samples were implanted in a murine air pouch and harvested after 14 days in situ. Pouch fluid was extracted, mRNA isolated, and reverse transcription polymerase chain reactions carried out to detect interleukin-1 gene expression as a marker for inflammation. In addition, multiple histological characteristics were examined to quantify cellular responses to the implanted materials. All bone graft substitutes induced a significant inflammatory response compared with negative controls. Histology and polymerase chain reaction data indicated that the level of inflammatory reaction was elevated in materials with a higher demineralized bone matrix to carrier proportion. The hydroxyapatite product generated a low inflammatory reaction. In conclusion, this study used an in vivo model of biocompatibility to demonstrate that a significant inflammatory reaction occurs when using implanted bone graft substitutes. When choosing a bone grafting method, surgeons should consider both the efficacy and safety of methods and materials used. Further studies are necessary to determine the ideal bone graft material to maximize efficacy while minimizing morbidity.
\end{abstract}

Keywords: bone graft, biocompatibility, inflammation, animal model

\section{Introduction}

Bone grafting is a ubiquitous tool of orthopedic surgery, because it is used in all subspecialties and in most anatomic regions. The bone source may be from the patient (autograft) or a cadaver (allograft). However, problems exist with both of these sources. Harvesting autograft bone prolongs the operative time and may cause significant donor-site complications. The use of allograft bone carries the added risk of disease transmission as well as the potential for inflammatory or immunologic reactions to foreign tissue.

Although autografts remain the gold standard for most bone grafting applications, recent advances have suggested that alternatives may be available that offer less potential morbidity. There have been significant advances in the development of bone graft substitutes over the past decade. If these substitutes can be demonstrated to be 
efficacious and safe, they provide an appealing alternative to conventional bone grafting techniques. ${ }^{1,2}$

The search for an ideal bone graft substitute was ignited in 1965, when Marshall Urist ${ }^{3}$ first discovered that demineralized bone matrix (DBM) implanted in muscle tissue induced bone growth. Since that time, Urist and others have promulgated the three properties that are used today to describe the activity of any bone graft material: osteoconductivity, osteoinductivity, and osteogenicity. These properties refer to a material that can provide a physical scaffold upon which bone can grow, that can stimulate new bone growth through various biochemical signaling events, and that can provide precursor cells or actual bone cells that can then, in turn, cause the propagation of new bone, respectively. ${ }^{4}$ The ideal bone graft would possess all three of these properties. For example, a fresh autograft possesses structure, necessary signaling molecules, and cells required to produce new bone. There are several engineered bone graft substitutes available now that possess some, but not all, of these properties. ${ }^{5,6}$ DBM has been shown to possess osteoconductive as well as osteoinductive properties. ${ }^{7,8}$ It has also been shown to cause new bone formation in vivo. ${ }^{9-13}$ Therefore, DBM represents a promising bone graft alternative, without the morbidities mentioned previously. ${ }^{14,15}$

Unfortunately, there are few or no clinical data to support the overall safety or efficacy of these products, particularly with regard to immunogenicity. Some products have been shown to cause adverse responses in vivo, including nephrotoxicity, likely due to the DBM carrier compound. ${ }^{16,17}$ Despite this lack of immunological data, the overall use of DBM products and the number of available products have grown rapidly. ${ }^{18}$ Therefore, further study appears necessary to substantiate that the product is safe and efficacious, in addition to determining the best preparation procedures and product formulation.

\section{Materials and methods Murine air pouch model}

The care and use of mice were approved by the Animal Investigation Committee of Wayne State University, Detroit, MI. The murine air pouch model for biocompatibility testing was used for this investigation. ${ }^{19}$ Air pouches were created in the dorsal subcutaneous tissue of female BALB/c mice. Initially, $3 \mathrm{~mL}$ of air was injected subcutaneously using a 25-gauge needle. Air pouches were injected with an additional $1 \mathrm{~mL}$ of air on alternate days for a total of 5 days. Implantation of the study materials was performed on the sixth day, when pouches were incised and test material was inserted into the pouch.
The pouches were then closed using 4-0 Prolene suture. As a prophylactic anti-infective, $0.3 \mathrm{~mL}$ of sterile phosphate buffered saline containing 1:100 penicillin:streptomycin solution was injected using a 25-gauge needle. Mice were randomly assigned to one of five groups of six mice. Pouches in the first group were incised and injected with sterile phosphate buffered saline solution. The second group was implanted with sterile $1.0 \mathrm{~mL}$ of ProOsteon ${ }^{\circledR}$ (Interpore Cross, Irvine, CA). This compound is a porous hydroxyapatite material representative of purely osteoconductive, coralline materials. The other three groups were implanted with sterile $1.0 \mathrm{~mL}$ of the DBM compounds DBX ${ }^{\circledR}$ (Synthes Inc, Paoli, PA), Accell Connexus $^{\circledR}$ (Isotis Orthobiologics, Irvine, CA), and Accell DBM-100 ${ }^{\mathrm{TM}}$ (Isotis Orthobiologics). DBX is approximately $32 \%$ DBM by weight in a sodium hyaluronate carrier. Accell Connexus contains $70 \%$ DBM in a proprietary "reverse-phase medium." Accell DBM-100 is 100\% DBM without carrier. All mice were sacrificed 14 days after implantation in a $\mathrm{CO}_{2}$ chamber. The pouches were dissected free from the subcutaneous tissues. Each pouch was then carefully cut in half, with half of the tissue fixed in formalin and half snap-frozen for nucleic acid extraction.

\section{Histologic evaluation and image analysis}

Tissue samples were fixed, dehydrated, and embedded in paraffin blocks. Particular care was taken to maintain the original shape and orientation of the sample relative to its position on the mouse. Sections were stained with hematoxylin and eosin to evaluate the cellular infiltrates within the pouch and pouch membrane. A minimum of four separate sections per specimen were examined using ImagePro image analysis software package (Media Cybernetics, Bethesda, MD). Pouch thickness was measured at six points distributed evenly along the circumference of each pouch. The density of nucleated cells was measured within the thickness of the pouch membrane and within the pouch cavity. The total number of cells was measured within at least four representative areas and divided by the area in $\mathrm{mm}^{2}$ to determine cellular density, as described previously. ${ }^{19}$ The image analysis utilized nuclear aspect ratio to distinguish between mononuclear and fibroblastic cell morphology, as described elsewhere. ${ }^{20}$ Visual identification and counting of macrophages and fibroblasts were also used to verify the data generated from the image analysis.

\section{Cytokine gene activation}

Activation of inflammatory cytokine genes was measured using reverse transcription-polymerase chain reactions (PCR). Gene expression of the proinflammatory cytokine interleukin-1 
(IL-1 $\beta$ ) was measured in cells obtained from the pouch fluid aspirate. Total RNA was extracted from this fluid according to the manufacturer's instructions (Tel-Test, Friendswood, TX). A cDNA library was constructed from $5 \mu \mathrm{g}$ RNA extract in $50 \mu \mathrm{L}$ solution containing $5 \mu \mathrm{L} 10 \mathrm{X}$ PCR buffer, $1 \mu \mathrm{L}$ $25 \mathrm{mM} \mathrm{MgCl}_{2}, 20 \mu \mathrm{L}$ deoxynucleotide triphosphates, 50 units RNase inhibitor, $5 \mu \mathrm{L}$ random hexamers, and 250 units reverse transcriptase (Perkin-Elmer Cetus, Norwalk, CT). The reaction mixture was incubated for 10 minutes at $25^{\circ} \mathrm{C}$, 25 minutes at $48^{\circ} \mathrm{C}$, and 5 minutes at $95^{\circ} \mathrm{C}$. The IL- 1 primer sequence was obtained from Clontech Laboratories Inc (Mountain View, CA). A total of $2 \mu \mathrm{L}$ of cDNA was combined with $25 \mu \mathrm{L}$ reaction solution containing $0.5 \mu \mathrm{L}$ primer pair, $2.5 \mu \mathrm{L}$ PCR buffer, $1.5 \mu \mathrm{L} \mathrm{MgCl}_{2}, 2 \mu \mathrm{L}$ nucleotide triphosphates (NTPs), and 1.25 U AmpliTaq DNA polymerase (Perkin-Elmer Cetus). PCR was initiated by heating at $94^{\circ} \mathrm{C}$ for 1 minute to denature RNA-cDNA hybrids, followed by annealing of the primers at $60^{\circ} \mathrm{C}$ for 1 minute and then extension of the primer sequences at $72^{\circ} \mathrm{C}$ for 1 minute. This sequence was repeated 35 times using the DNA thermal cycler (Perkin-Elmer Cetus). Following amplification, $10 \mu \mathrm{L}$ of each reaction solution was mixed with $1 \mu \mathrm{L}$ loading buffer for agarose gel electrophoresis. Densities of cytokine bands were measured using ultraviolet light and the ISO 2000 Digital Imaging System (Alpha Innotech, San Leandro, CA). All cytokine levels were normalized using the PCR product from the housekeeping gene GAPDH.

\section{Statistics}

The analysis of variance (ANOVA) test with post hoc analysis using the least significant difference formula was used to compare means for all histological parameters, including membrane thickness, density of cellular infiltrate within the pouch membrane, and density of cellular infiltrate within the cavity of the pouch. When the overall F-test for differences among treatment means was significant, pairwise comparisons of treatment means were conducted. For the PCR data, single-factor ANOVA was again used to test for differences among means. When the overall F-test was significant, treatment means were compared using Student's $t$-test. All results were considered significant for $P<0.05$.

\section{Results}

\section{Air pouch membrane}

The histological characteristics of the air pouch membrane were assessed for each of the implanted substances and compared with the saline control, because the inflammatory response to implanted biomaterials can be characterized by increases in both the membrane thickness and the density of cellular infiltrate within the membrane wall. In salinetreated mice, the air pouch membrane was characterized by an outer fibrous layer composed primarily of fibroblastic cells and an inner portion composed of inflammatory cells, predominantly macrophages (Figure 1A). The membranes had a mean thickness of $47.7 \mu \mathrm{m}$ and a cell number of 83.4 cells $/ \mathrm{mm}^{2}$. As shown in Figure 2, pairwise comparisons showed a significantly higher membrane thickness for each bone graft substitute when compared with the saline control $(P<0.05)$. Additionally, the ProOsteon and the DBX had significantly thicker membranes than either of the Accell bone graft substitutes $(P<0.05)$. No other mean differences between compounds were significant. The cellular density within the air pouch membrane walls did not differ between the saline control and any of the compounds tested using single-factor ANOVA (data not shown).

\section{Air pouch cellular infiltrate}

The density of the cellular infiltrate was examined within the air pouch cavity. The cavities of the test compounds each contained regions of immature bone as well as regions of dense cellular infiltrates (see Figure 1B-E). As shown in Figure 3, using pairwise comparisons, a statistically significant differ-

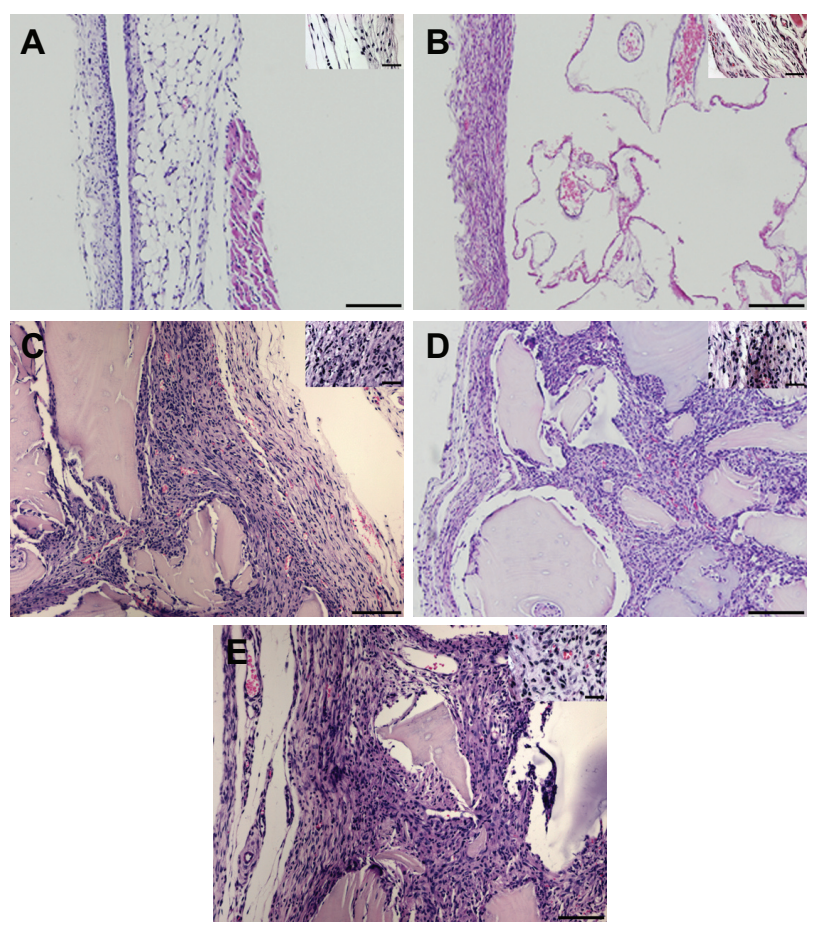

Figure I The histological appearance of air pouch membranes from mice implanted with saline $(\mathbf{A})$, ProOsteon ${ }^{\circledR}(\mathbf{B}), \mathrm{DBX}^{\circledR}(\mathbf{C})$, Accell Connexus ${ }^{\circledR}(\mathbf{D})$, and Accell DBM-100 $1 \mathrm{TM}(\mathbf{E})$. Original magnification $=50 \times(\mathbf{A}, \mathbf{B}, \mathbf{D})$ or $100 \times(\mathbf{C}, \mathbf{E})$ for larger photographs (Bars $=500$ microns), $200 \times$ for smaller insets (Bars $=100$ microns). 


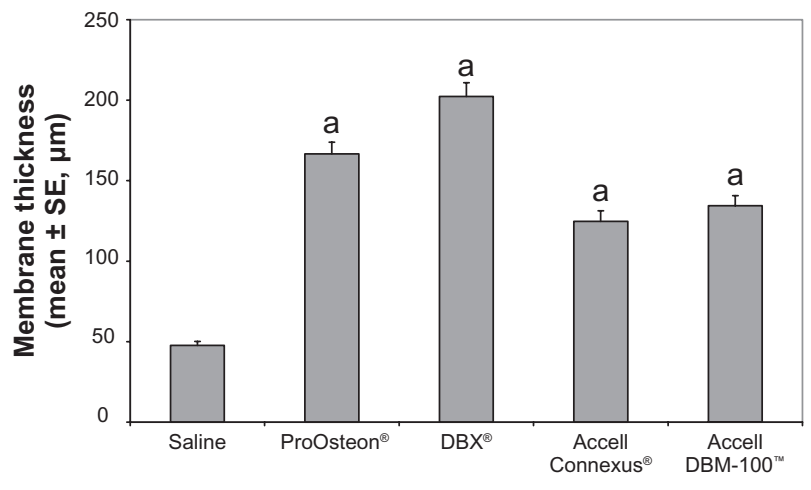

Figure 2 Membrane thickness of control and bone graft substitute-stimulated air pouches.

Notes: a $P<0.05$ versus saline control. $\mathrm{n}=6$ mice/group.

Abbreviation: SE, standard error

ence in the density of the cellular infiltrate was observed among all groups $(P<0.05)$. ProOsteon showed significantly less cellular infiltration than all of the DBM products. Among the DBM products, there was an increasing density of the cellular infiltrate as the ratio of DBM to carrier increased. The ratio of macrophage/monocytes to fibroblasts in the infiltrate was determined using image analysis as previously described. ${ }^{20}$ Significantly elevated numbers of monocytes were observed in pouch tissues associated with Accell Connexus and Accell DBM-100 (Figure 4) when compared with the control tissue $(P<0.05)$, whereas the ratios of monocytes:fibroblasts in pouch tissues associated with ProOsteon and DBX were not significantly different from control pouch tissues.

\section{Cytokine gene activation in the air pouch}

Reverse transcription-PCR was performed using the mRNA extracted from cells within the pouch fluid. Murine IL-1 primers were used to determine IL-1 expression as a marker to quantify the inflammatory reaction within the cavity of the pouch. Results are shown in Figure 5. Compared with

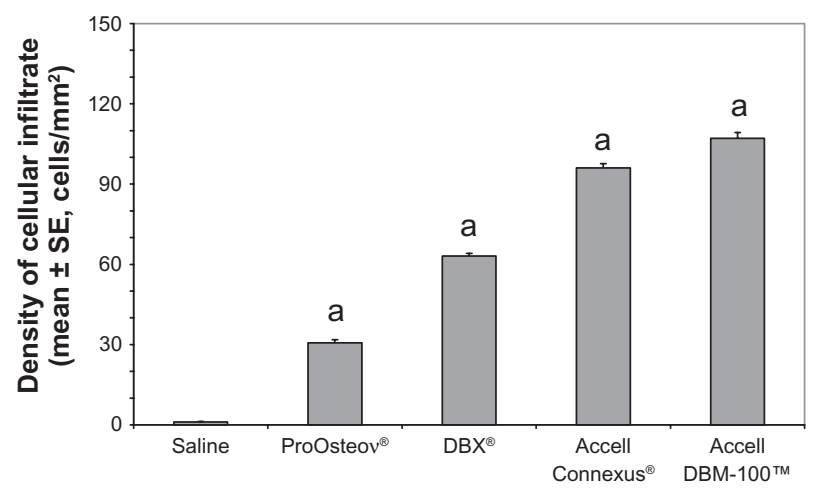

Figure 3 Membrane cellularity within the cavity of the pouch of control and bone graft substitute-stimulated mice.

Notes: ${ }^{a} P<0.05$ versus saline control. $n=6$ mice/group.

Abbreviation: SE, standard error

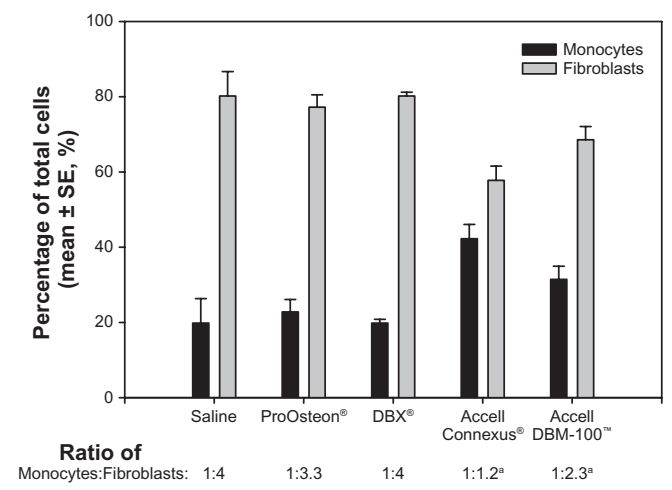

Figure 4 Ratio of macrophages/monocytes to fibroblasts within the air pouch of control and bone graft substitutes.

Notes: a $P<0.05$ versus saline control. $\mathrm{n}=6$ mice/group.

Abbreviation: SE, standard error

the saline control, all compounds showed significantly higher levels of IL-1 expression $(P<0.05)$. The highest level of IL-1 expression was observed in the Accell DBM100-containing air pouches; the increased expression was statistically significant when compared with both ProOsteon and Accell Connexus $(P<0.05)$.

\section{Discussion}

Recent studies have helped to clarify the optimum makeup of DBM products, including the source of allograft, preparation methods, particle size, and different carrier substances. ${ }^{21}$ Several studies have suggested that differing methods of graft preparation can cause differences in efficacy. ${ }^{14,22}$ Unfortunately, few studies have examined how differences in bone graft substitute production may cause variations in biocompatibility with adverse effects.

All DBM products are prepared from bone allografts that are first treated with a variety of washes, antibiotic treatments, irradiation, and other treatments to remove potentially infectious agents. In addition to removing bacterial contaminants,

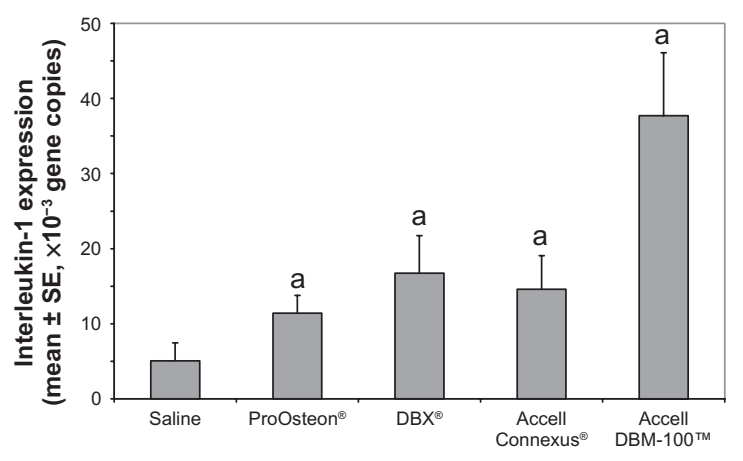

Figure 5 Interleukin-I gene copies produced using reverse transcription-polymerase chain reaction with $\mathrm{mRNA}$ extracted from the air pouches of control and bone graft substitute-stimulated mice.

Notes: ${ }^{a} P<0.05$ versus saline control. $\mathrm{n}=6$ mice/group.

Abbreviations: SE, standard error; mRNA, messenger ribonucleic acid. 
Table I Summary of data from histological analyses and reverse transcription-polymerase chain reaction analysis

\begin{tabular}{|c|c|c|c|c|}
\hline $\begin{array}{l}\text { Bone graft } \\
\text { substitute }\end{array}$ & $\begin{array}{l}\text { Membrane thickness } \\
(\text { mean } \pm \mathrm{SE}, \mu \mathrm{m})\end{array}$ & $\begin{array}{l}\text { Pouch density } \\
\left(\text { mean } \pm \mathrm{SE} \text {, cells } / \mathrm{mm}^{2}\right)\end{array}$ & $\begin{array}{l}\text { Macrophages/monocytes: } \\
\text { fibroblasts }\end{array}$ & $\begin{array}{l}\text { Interleukin-I expression } \\
\text { (mean } \pm \mathrm{SE} \text {, copies) }\end{array}$ \\
\hline Saline & $47.7 \pm 2.4$ & $1.0 \pm 0.2$ & $\mathrm{I}: 4$ & $50,609 \pm 24,083$ \\
\hline ProOsteon ${ }^{\circledast}$ & $166.7 \pm 7.2$ & $30.7 \pm 1.2$ & $\mathrm{I}: 3.3$ & $113,930 \pm 23,715$ \\
\hline $\mathrm{DBX}^{\circledR}$ & $202.3 \pm 8.7$ & $63.1 \pm 1.0$ & $\mathrm{I}: 4$ & $167,203 \pm 50,079$ \\
\hline Accell Connexus ${ }^{\circledR}$ & $124.8 \pm 6.5$ & $96.0 \pm 1.6$ & $\mathrm{I}: 1.3$ & $|46| 1 \mid, 5 \pm 44,487$ \\
\hline Acell DBM- $100^{\mathrm{TM}}$ & $134.4 \pm 6.3$ & $107.7 \pm 2.2$ & $\mathrm{I}: 2.3$ & $377,137 \pm 83,669$ \\
\hline
\end{tabular}

Abbreviation: SE, standard error.

processing has been shown to inactivate multiple infectious viruses, including human immunodeficiency virus, hepatitis $\mathrm{B}$ and $\mathrm{C}$ viruses, and cytomegalovirus. ${ }^{23,24} \mathrm{It}$ is not yet clear whether differences in efficacy result from differences in the carriers or are as a result of other differences in preparation. The tissue is then demineralized using an acid solution, usually hydrochloric acid. Finally, the DBM is then mixed with a carrier to alter the texture, viscosity, and other characteristics of the final packaged product.

There are other factors that can affect the efficacy and safety of DBM products. Animal and human studies have shown that the age of the donor can significantly impact the osteoinductive potential for DBM. ${ }^{25,26}$ There are also significant differences in the type of carrier used and in the concentration of DBM within that carrier. Different carriers include glycerol, porcine collagen, hyaluronic acid, lecithin, calcium sulfate, or no carrier at all. Most DBM products contain approximately $20 \%-40 \%$ DBM by weight. In addition to the carrier substance in the DBM product, some investigators have also looked at various additional delivery systems added at the time of implantation to further alter the physical properties of the DBM. ${ }^{27,28}$ The fact that there are so many different materials and techniques used to manufacture similar products all intended for the same purpose means that the ideal makeup of a bone graft substitute is as yet undefined.

This study was designed to examine the inflammatory characteristics of several commercially available bone graft substitutes. Three demineralized bone graft products and one synthetic hydroxyapatite compound were studied using the murine air pouch. ${ }^{19}$ Overall, all products showed a significant inflammatory response within the pouch when compared with the saline control (summarized in Table 1). The hydroxyapatite material showed less inflammation than the DBM products. Within the DBM products tested, there was a trend toward increasing inflammation with increasing DBM concentration. The precise mechanism for this relationship remains to be determined and should be addressed in the clinical setting, given that a wide variety of DBM products with different DBM to carrier ratios are available.
With regard to the efficacy of different DBM products, Peterson et $\mathrm{al}^{29}$ recently published a study comparing multiple commercially available DBM products using an animal spinal fusion model with three different DBM preparations. They showed significant differences in the fusion rate and osteoinductive activity seen on histological sections. ${ }^{29}$ The animal model utilized immunoincompetent, athymic mice, which unfortunately precluded the evaluation of any effects of immune-provoked inflammation on osteoinductivity.

There were two weaknesses to our model of testing for the inflammatory reaction induced by bone graft substitutes. First, an animal model was employed. Any analogies to human biology must be made with caution. Species-specific reactivity to biomaterials should be considered. Specifically, the DBM products were derived from human tissue and theoretically could elicit a xenograft reaction not pertinent to human implantation. Second, this study was designed to elucidate the inflammatory reaction caused by these materials, and the cytokine evaluation was restricted to the measurement of IL-1 $\beta$, the major mediator elicited in the murine inflammatory air pouch. No assertions were made relative to their efficacy. Therefore, one should use caution when extrapolating from the data presented here to determine the ideal bone graft substitute. Further studies are needed to discover the ideal formulation for a bone graft substitute. A follow-up to this study could include the examination of additional bone graft substitutes. Moreover, bone tissue can be implanted within the air pouch with bone graft substitute materials to quantify bone induction and production. Ultimately, randomized, prospective clinical trials comparing these products should be undertaken. However, studies such as ours help shed some light on the complex biology of bone graft substitutes.

\section{Conclusion}

By both histologic and biochemical markers, our results indicate that all the products investigated provoked a significant inflammatory reaction when compared with the saline control. DBM products showed more inflammation than coralline 
hydroxyapatite. Within the DBM groups, there was a trend toward increasing inflammation with increasing DBM concentration. Therefore, our preliminary findings suggest that DBM products with varied DBM proportions may influence the level of biocompatibility during clinical use.

\section{Disclosure}

The authors report no conflicts of interest in this work.

\section{References}

1. Finkemeier CG. Bone-grafting and bone-graft substitutes. J Bone Joint Surg Am. 2002;84-A:454-464.

2. Iwata H, Sakano S, Itoh T, Bauer TW. Demineralized bone matrix and native bone morphogenetic protein in orthopaedic surgery. Clin Orthop Relat Res. 2002;395:99-109.

3. Urist MR. Bone: formation by autoinduction. Science. 1965;150: 893-899.

4. Bauer TW, Muschler GF. Bone graft materials. An overview of the basic science. Clin Orthop Relat Res. 2000;371:10-27.

5. Bucholz RW. Nonallograft osteoconductive bone graft substitutes. Clin Orthop Relat Res. 2002;395:44-52.

6. Vaccaro AR, Chiba K, Heller JG, et al. Bone grafting alternatives in spinal surgery. Spine J. 2002;2:206-215.

7. Oakes DA, Lee CC, Lieberman JR. An evaluation of human demineralized bone matrices in a rat femoral defect model. Clin Orthop Relat Res. 2003;413:281-290.

8. Einhorn TA, Lane JM, Burstein AH, Kopman CR, Vigorita VJ. The healing of segmental bone defects induced by demineralized bone matrix. A radiographic and biomechanical study. J Bone Joint Surg Am. 1984;66:274-279.

9. Han B, Tang B, Nimni ME. Quantitative and sensitive in vitro assay for osteoinductive activity of demineralized bone matrix. J Orthop Res. 2003;21:648-654.

10. Edwards JT, Diegmann MH, Scarborough NL. Osteoinduction of human demineralized bone: characterization in a rat model. Clin Orthop Relat Res. 1998;357:219-228.

11. An HS, Simpson JM, Glover JM, Stephany J. Comparison between allograft plus demineralized bone matrix versus autograft in anterior cervical fusion. A prospective multicenter study. Spine. 1995;20:2211-2216.

12. Feighan JE, Davy D, Prewett AB, Stevenson S. Induction of bone by a demineralized bone matrix gel: a study in a rat femoral defect model. J Orthop Res. 1995;13:881-891.

13. Ladd AL, Pliam NB. Use of bone-graft substitutes in distal radius fractures. J Am Acad Orthop Surg. 1999;7:279-290.

14. Russell JL, Block JE. Clinical utility of demineralized bone matrix for osseous defects, arthrodesis, and reconstruction: impact of processing techniques and study methodology. Orthopedics. 1999;22:524-531.
15. Yoon ST, Boden SD. Osteoinductive molecules in orthopaedics: basic science and preclinical studies. Clin Orthop Relat Res. 2002;395:33-43.

16. Bostrom MP, Yang X, Kennan M, Sandhu H, Dicarlo E, Lane JM. An unexpected outcome during testing of commercially available demineralized bone graft materials: how safe are the nonallograft components? Spine. 2001;26:1425-1428.

17. Wang JC, Kanim LE, Nagakawa IS, Yamane BH, Vinters HV, Dawson EG. Dose-dependent toxicity of a commercially available demineralized bone matrix material. Spine. 2001;26:1429-1435.

18. Seeherman H, Li R, Wozney J. A review of preclinical program development for evaluating injectable carriers for osteogenic factors. $J$ Bone Joint Surg Am. 2003;85-A:96-108.

19. Wooley PH, Morren R, Andary J, et al. Inflammatory responses to orthopaedic biomaterials in the murine air pouch. Biomaterials. 2002;23:517-526

20. Ottaviani RA, Wooley P, Song Z, Markel DC. Inflammatory and immunological responses to hyaluronan preparations: study of a murine biocompatibility model. J Bone Joint Surg Am. 2007;89:148-157.

21. Maddox E, Zhan M, Mundy GR, Drohan WN, Burgess WH. Optimizing human demineralized bone matrix for clinical application. Tissue Eng. 2000;6:441-448.

22. Takikawa S, Bauer TW, Kambic H, Togawa D. Comparative evaluation of the osteoinductivity of two formulations of human demineralized bone matrix. J Biomed Mater Res A. 2003;65:37-42.

23. Swenson CL, Arnoczky SP. Demineralization for inactivation of infectious retrovirus in systemically infected cortical bone: in vitro and in vivo experimental studies. J Bone Joint Surg Am. 2003; 85-A:323-332.

24. Ad Hoc Working Party on Biotechnology/Pharmacy. Validation of virus removal and inactivation procedures. Pharmacol Toxicol. 1991;69:144-148

25. Pinholt EM, Solheim E. Osteoinductive potential of demineralized rat bone increases with increasing donor age from birth to adulthood. J Craniofac Surg. 1998;9:142-146.

26. Nyssen-Behets C, Delaere O, Duchesne PY, Dhem A. Aging effect on inductive capacity of human demineralized bone matrix. Arch Orthop Trauma Surg. 1996;115:303-306.

27. Damien CJ, Parsons JR, Prewett AB, Rietveld DC, Zimmerman MC. Investigation of an organic delivery system for demineralized bone matrix in a delayed-healing cranial defect model. J Biomed Mater Res. 1994;28:553-561.

28. Jazayeri MA, Nichter LS, Zhou ZY, Wellisz T, Cheung DT. Comparison of various delivery systems for demineralized bone matrix in a rat cranial defect model. J Craniofac Surg. 1994;5:172-178.

29. Peterson B, Whang PG, Iglesias R, Wang JC, Lieberman JR. Osteoinductivity of commercially available demineralized bone matrix. Preparations in a spine fusion model. J Bone Joint Surg Am. 2004;86-A: $2243-2250$
Journal of Inflammation Research

\section{Publish your work in this journal}

The Journal of Inflammation Research is an international, peer-reviewed open-access journal that welcomes laboratory and clinical findings on the molecular basis, cell biology and pharmacology of inflammation including original research, reviews, symposium reports, hypothesis formation and commentaries on: acute/chronic inflammation; mediators of inflamma-

\section{Dovepress}

tion; cellular processes; molecular mechanisms; pharmacology and novel anti-inflammatory drugs; clinical conditions involving inflammation. The manuscript management system is completely online and includes a very quick and fair peer-review system. Visit http://www.dovepress.com/ testimonials.php to read real quotes from published authors. 